\title{
HUMAN BONE-CELL PROLIFERATION IN VITRO DECREASES WITH HUMAN DONOR AGE
}

\author{
YOICHI SHIGENO, BRIAN A. ASHTON \\ From the Robert Jones and Agnes Hunt Orthopaedic and District Hospital, Oswestry, England
}

We have measured the effect of age on the rate of outgrowth of cells from human trabecular bone, using a quantitative dye-binding technique.

In cultures supplemented with autologous serum, there were significant negative correlations between the age of the donor and both the proportion of fragments from which outgrowths were seen after 7 days $(r=-0.70 ; p<0.001)$ and the total cell number after 14 days $(r=-0.78 ; p<0.005)$. The autologous serum supported greater cell proliferation than did fetal calf serum in all subjects regardless of age.

Taken with previous observations that the in vitro growth kinetics of passaged human bone cells are independent of age, our results show that the number of proliferative precursor cells on trabecular-bone surfaces is higher in younger subjects. There is a marked decrease in precursor numbers in the second and third decades of life to a level which is maintained into old age.

J Bone Joint Surg /Br/ 1995:77-B:139-42.

Received 16 October 1992; Accepted 17 June 1994

It is well known that fracture healing is faster in young patients than in the elderly, but it is not clear whether this results from changes in the number of osteogenic precursor cells in bone or from changes in the kinetics of cell proliferation. Changes in cell-cycle time may be genetically programmed or be secondary to local or systemic changes in hormonal and growth-factor status.

Previous studies have failed to show a clear relationship between the age of human donors and the rate of bone-cell proliferation in vitro by measurement of $\left[{ }^{3} \mathrm{H}\right]$-thymidine incorporation (Evans, Galasko and Ward 1990; Knight and

Y. Shigeno, MD, Research Fellow

B. A. Ashton, DPhil, Head of Research

Department of Rheumatology, the Robert Jones and Agnes Hunt Orthopaedic and District Hospital. Oswestry, Shropshire SY10 7AG, UK.

Correspondence should be sent to Dr Y. Shigeno at the Division of Orthopaedic Surgery, Kure National Hospital, 3-1 Aoyama-Cho, Kure, Hiroshima 737, Japan.

(1)1995 British Editorial Society of Bone and Joint Surgery

$0301-620 \mathrm{X} / 95 / 1914 \$ 2.00$
Gowen 1992). We have used a different technique to study this relationship.

\section{MATERIALS AND METHODS}

Trabecular-bone specimens were collected from normal iliac bone used for surgical grafting in 20 patients aged from 5 to 70 years. Great care was taken not to damage the specimen and it was cut into small pieces of about $2 \mathrm{~mm}$ in the largest dimension using bone rongeurs. The fragments were washed free of marrow cells with three changes of Minimum Essential Medium overnight.

For the cultures we used Minimum Essential Medium with Earle's salts and L-glutamine (Life Technologies Ltd, Paisley, UK) with 50 units $/ \mathrm{ml}$ of benzyl penicillin, $50 \mu \mathrm{g} /$ $\mathrm{ml}$ of streptomycin sulphate, and 50 units $/ \mathrm{ml}$ of nystatin. The trabecular-bone specimens were plated out at one fragment per $1.9 \mathrm{~cm}^{2}$ well (4-well multidish; Nunc, Life Technologies Ltd) in $1 \mathrm{ml}$ of culture medium supplemented with either $10 \%$ autologous serum taken preoperatively or $10 \%$ fetal calf serum, with 8 replicates/variable. Cultures were maintained at $37^{\circ} \mathrm{C}$ in a humidified atmosphere of $5 \%$ $\mathrm{CO}_{2}$ in air.

At 7 days, we evaluated microscopic evidence of cell proliferation on the bone fragment and on the well surface. When at least five fibroblastic cells were found on the well surface the result was scored as positive, if less than five as negative. After evaluation the culture medium was replenished, taking great care not to move the bone fragments.

At 14 days, the medium was removed and the wells rinsed with phosphate-buffered saline, fixed with $0.5 \mathrm{ml}$ of 95\% methanol for ten minutes and air-dried.

Dye-binding assay. The number of cells was assessed in a dye-binding assay (Gillies, Didier and Denton 1986). Wells were stained for three minutes at room temperature with $1 \mathrm{ml}$ of $1 \%$ crystal violet solution in deionised water. The unbound dye was removed and the well washed thoroughly with distilled water for two minutes and air-dried.

Destaining solution $(250 \mu \mathrm{l}$ of $95 \%$ methanol containing $40 \mathrm{mM}$ hydrochloric acid) was added to each well and shaken gently until all the stain had been extracted. Duplicate $100 \mu \mathrm{l}$ aliquots were transferred to a flat-bottomed 96microwell plate (Nunc; Life Technologies Ltd). To prevent evaporation error, the transferred $100 \mu \mathrm{l}$ aliquots were evaporated completely, and the stain redissolved in $200 \mu \mathrm{l}$ 


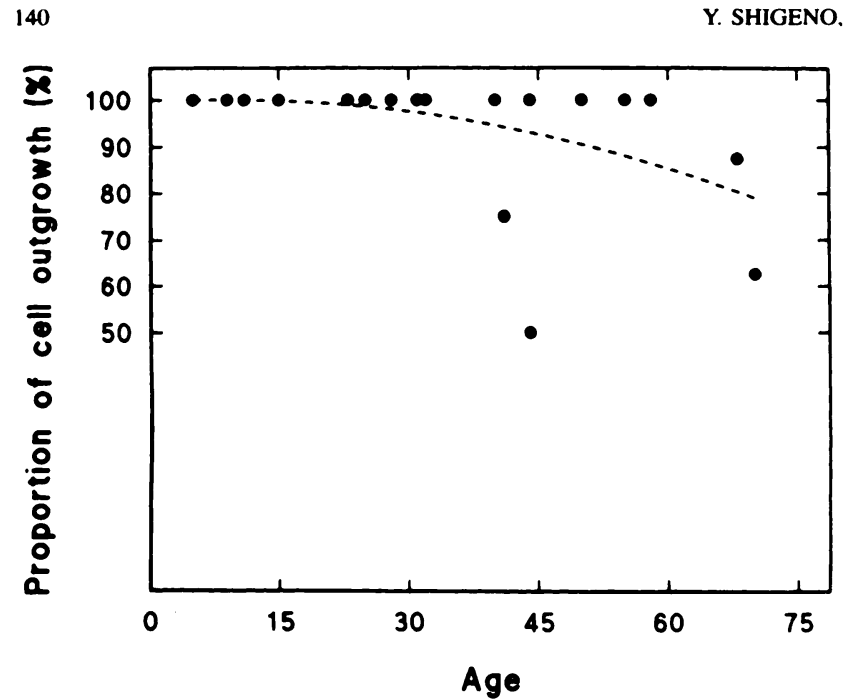

Fig. 1

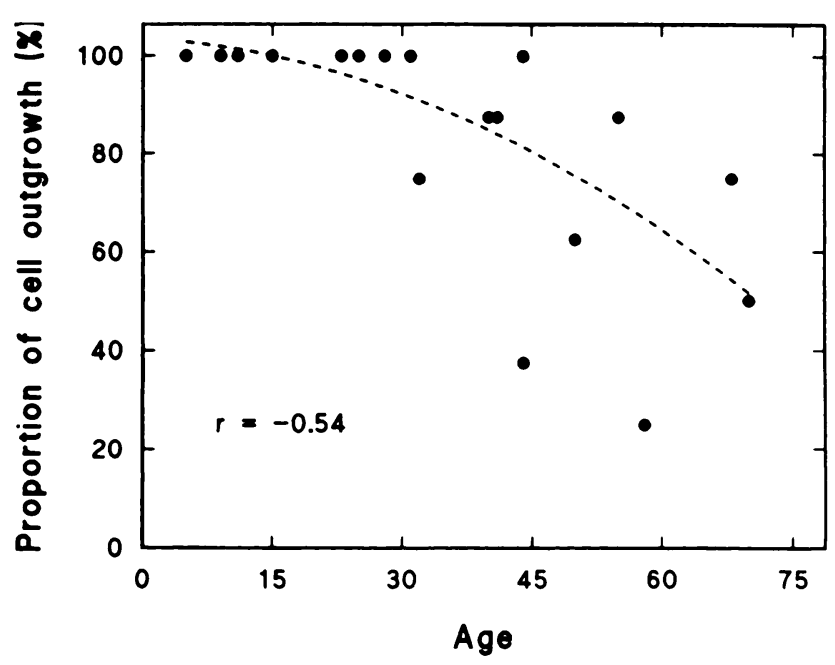

Fig. 2

Effect of donor age on the proportion of fragments showing proliferation on the bone surface after culture for 7 days. Figure 1 - In fetal calf serum Figure 2 - In autologous serum.

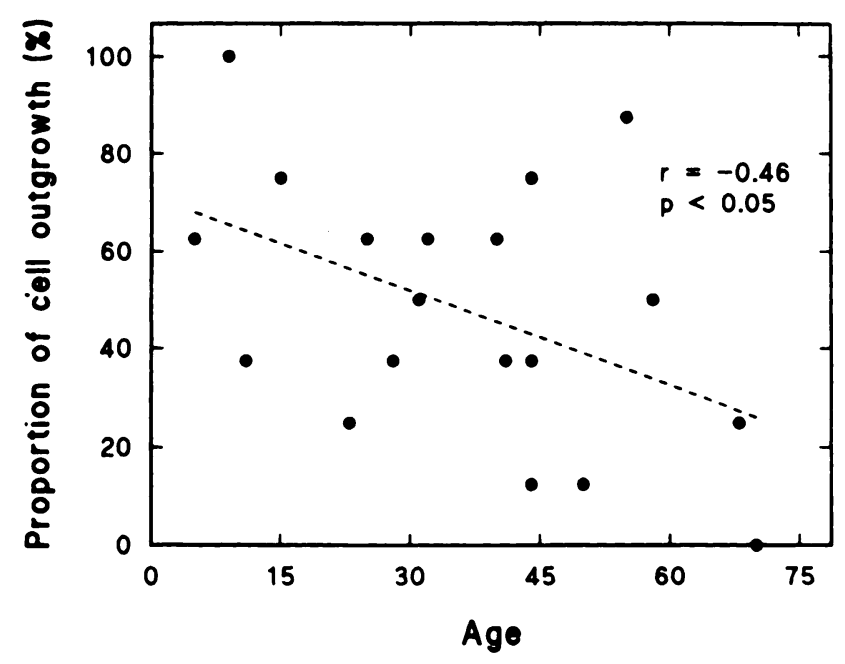

Fig. 3

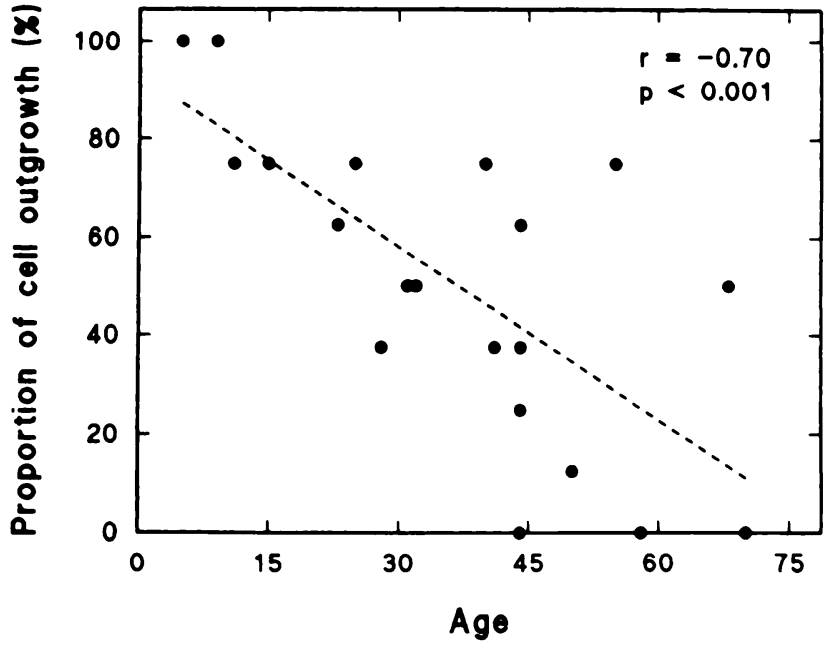

Fig. 4

Effect of donor age on the proportion of wells with cell outgrowth on to the well surface after culture for 7 days. Figure 3 - In fetal calf serum. Figure 4 - In autologous serum.

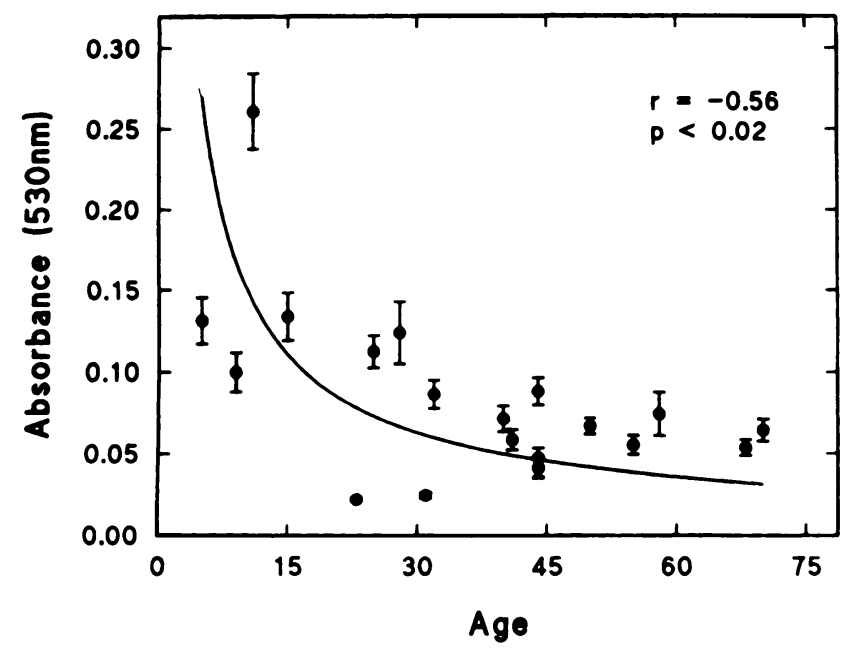

Fig. 5

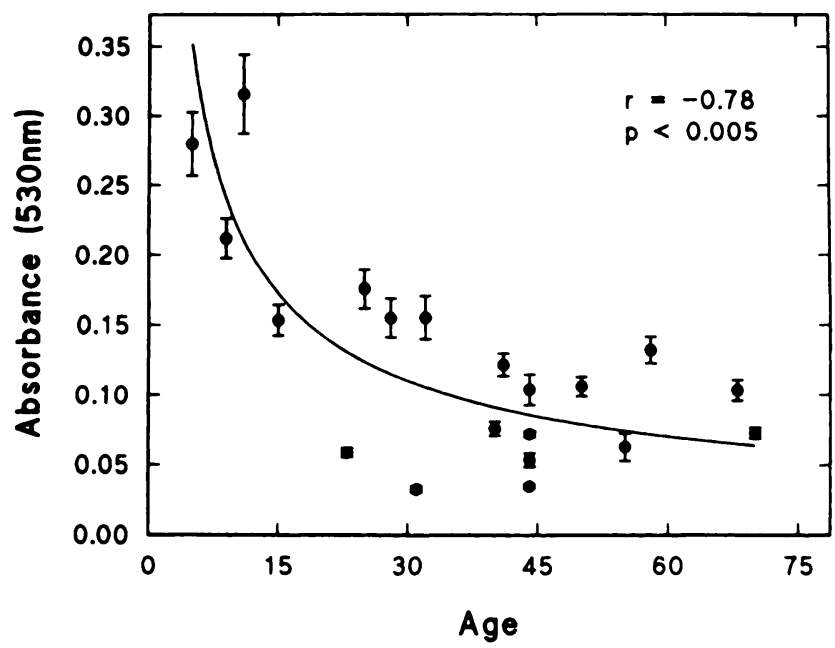

Fig. 6

Regression of cell numbers at 14 days in relation to donor age. Figure 5 - In fetal calf serum. Figure 6 - In autologous serum. 


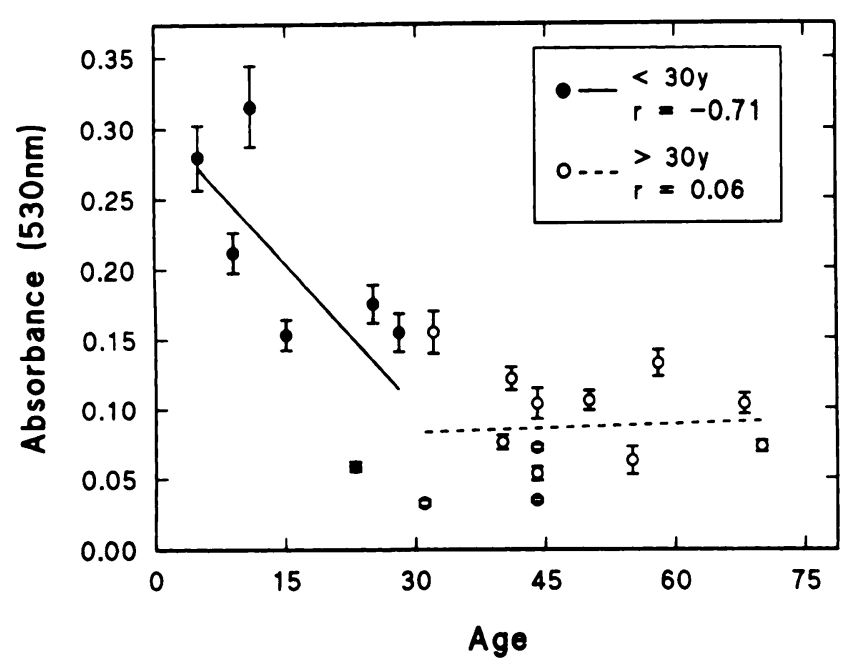

Fig. 7

Regression of cell numbers with autologous serum for donors under 30 years and over 30 years old.

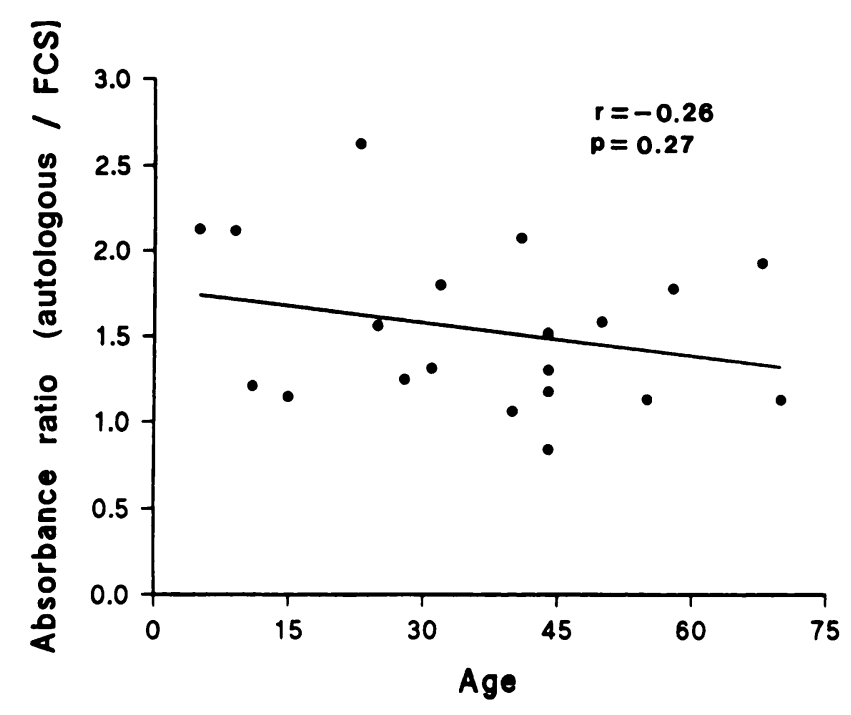

Fig. 9

Regression of the relative effects of autologous serum and fetal calf serum (FCS) in relation to donor age.

of destaining solution immediately before the optical density at $530 \mathrm{~nm}$ was measured directly in a microplate photometer (EL312; Bio-tek Instruments, Winooski, Vermont).

\section{RESULTS}

Trabecular-bone fragments which had been washed overnight in three changes of culture medium were substantially free of marrow elements regardless of the age of the donor. Cellular proliferation could be seen on some trabecularbone surfaces as early as three days after plating; outgrowth onto the well occurred from the fifth day onwards.

At day 7 , the proportion of fragments grown in fetal calf serum which had proliferation on the bone surface, showed

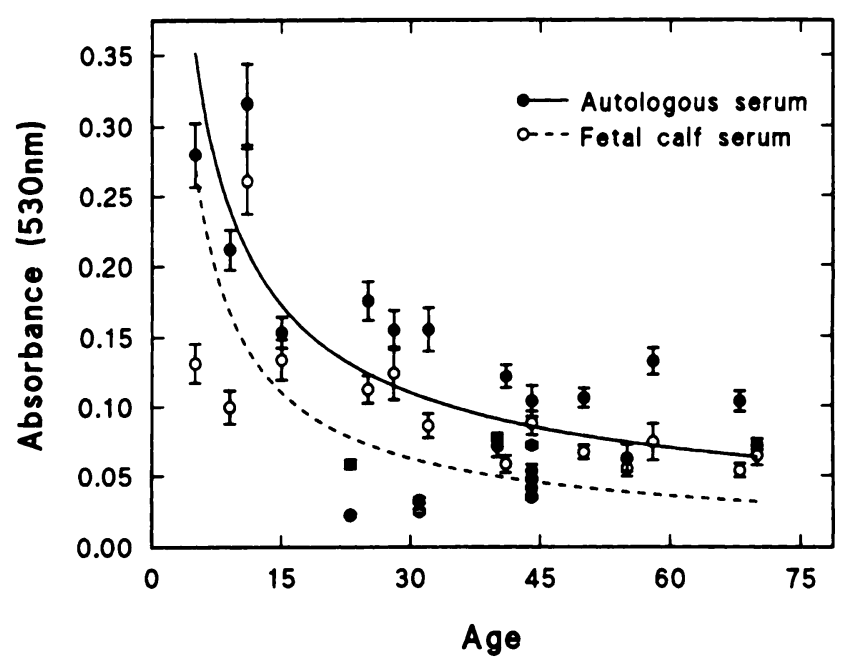

Fig. 8

Regression of cell numbers in relation to donor age comparing the effects of autologous serum and fetal calf serum.

no significant difference with donor age (Fig. 1). In those grown in autologous serum, however, there was an agerelated decrease in the proportion of fragments showing proliferation on the bone surface, especially after the third decade $(r=-0.54 ;$ Fig. 2$)$. There was an age-related decrease in the proportion of wells with cellular outgrowth on to the plastic surface in both fetal calf serum $(r=-0.46$; $p<0.05$; Fig. 3) and autologous serum $(r=-0.70$; p $<0.001$; Fig. 4).

Between 7 and 14 days there were increases in cell numbers on both the bone and well surfaces. At 14 days, cell numbers showed a significant inverse correlation with donor age in both fetal calf and autologous sera (Figs 5 and 6). This was more obvious in the first three decades of life, becoming more constant thereafter (Fig. 7). Autologous serum supported significantly greater cell proliferation than fetal calf serum ( $p<0.0005$; Fig. 8 ), and the ratio of the extent of outgrowth in autologous serum to that in fetal calf serum was independent of age (Fig. 9).

\section{DISCUSSION}

For many years, the long time required for fracture repair in older patients has been regarded as being due to slow wound healing, reflecting a general functional decline in the homeostatic mechanisms during ageing. Cell proliferation, migration and differentiation are the vital stages of fracture repair and may be influenced by genetic factors, interaction with the extracellular matrix, and by local hormonal and growth-factor levels.

Our studies have shown that the proliferative potential of cells on trabecular-bone surfaces is high in young patients, and shows a marked decrease in the second and third decades of life to a level maintained into old age.

The growth kinetics of passaged human bone cells in vitro have been found to be independent of donor age 
(Evans et al 1990; Knight and Gowen 1992). This means that, within a given time, one proliferative cell in the bone from a five-year-old will yield the same number of progeny as one proliferative cell from the bone of an 80-year-old. The age-related decrease in cellular outgrowth that we report must result from a decrease in the number of proliferative precursors present on the bone surface. Since osteoblasts and bone-lining cells have very low or no proliferative capacity (Owen 1978), the cellular outgrowths are probably derived from less-differentiated precursors related to marrow CFU-F which also undergo an agerelated decrease (Bab et al 1988).

Fetal calf serum, a standard supplement for in vitro culture media, is rich in growth factors. It is therefore interesting that autologous serum supported greater cell division than did fetal calf serum and that the relative efficiencies of the two sera did not change with age. This suggests that changes in the systemic or local availability of growth factor are not the cause of age-related changes in bone-cell proliferation.

No benefits in any form have been received or will be received from a commercial party related directly or indirectly to the subject of this article.

\section{REFERENCES}

Bab I, Passi-Even L, Gazit D, et al. Osteogenesis in in-vivo diffusion chamber cultures of human marrow cells. Bone Miner 1988:4:373-86.

Evans CE, Galasko CS, Ward C. Effect of donor age on the growth in vitro of cells obtained from human trabecular bone. $J$ Orthop Res 1990:8:234-7.

Gillies RJ, Didier N, Denton M. Determination of cell number in monolayer cultures. Anal Biochem 1986;159:109-13.

Knight SM, Gowen M. The effect of age and sex on bone cell function. Calcif Tissue Int 1992;50:Suppl I A12.

Owen M. Histogenesis of bone cells. Calcif Tissue Res 1978:25:205-7. 